\title{
Sustainable development and optimization of internal control of business processes of companies
}

\author{
Nagumanova Regina Vildanovna \\ $\mathrm{PhD}$ in economics, Associate Professor, \\ Kazan Federal University, Institute of Management, \\ Economics and Finance \\ Kazan, 420008, Russia \\ nagumanova22@yandex.ru \\ Sabirova Aigyl Ilshatovna \\ Senior Lecturer, \\ Kazan Federal University, Institute of Management, \\ Economics and Finance \\ Kazan, 420008, Russia \\ aigylkinyes@mail.ru
}

\author{
Naumova Natalia Alexandrovna \\ $\mathrm{PhD}$ in economics, Senior Lecturer, \\ Kazan Federal University, Institute of Management, \\ Economics and Finance \\ Kazan, 420008, Russia \\ naumovanataliy@mail.ru
}

\author{
Titova Nadezhda Georgievna \\ $\mathrm{PhD}$ in philology, Associate Professor,
}

The Russian Presidential Academy of National Economy and

Public Administration,

Moscow, 119571, Russia

ng.titova@mail.ru

\section{INTRODUCTION}

Abstract-The article deals with the approach of inner control of business processes "from purchase to payment" that allows one to monitor the dynamics and factual achievement of set targets. The article gives the description of the interaction of the internal audit object and business processes "from purchase to payment". It suggests the scheme of conducting an electronic poll procedure represented in the form of a context diagram constructed by means of such methodology of functional modeling as IDEFO. The recommended approach allows one to make an overall analysis of the state of an audited object (process) and the results of its functioning; to reveal problems and reasons of failures as well as to work out the peculiar measures aimed to improve the functioning of not only the given process but the process of an internal audit as well.

Key words-Internal audit, business process, control, efficiency of an internal audit, business, sustainable development.
The examination of all company units that take part in a business process "from purchase to payment" without defining the results of their functioning and revealing weaknesses and problems is a difficult matter. It implies the expenses of a large amount of human and time resources. During the procedure of the audit object selection company units (contiguous business processes) that play the role of "Suppliers" and "Consumers" for the given process are selected as well. In order to realize this procedure it is necessary to distinguish processes, to regularize responsibilities and powers, i.e. to specify the "owners" of the process, to devise schemes for each process and general process network that shows information and product flows providing the cooperation and functioning of business processes "from purchase to payment".

Figure 1 shows the fragment of the general scheme of cooperation of business processes "from purchase to payment".

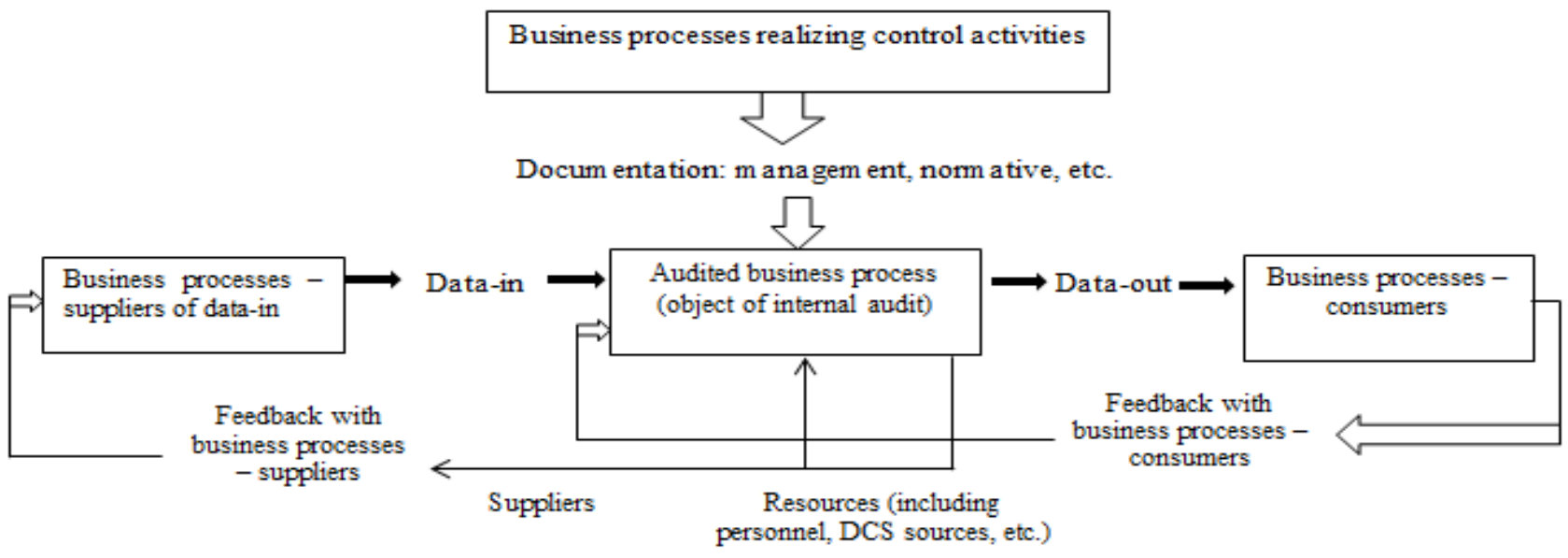

Fig. 1. Cooperation of an internal audit object with business processes "from purchase to payment". 


\section{METHOD}

Target group is a group of collaborators, the representatives of the process. The procedure of its formation involves the appointment of company officials, the employees of a joint-stock company "HR", who will carry out an audit work of a given object. A target group is a reflection (projection) of an audited process and contiguous processes on the personnel. A target group is necessary when carrying out an internal audit and analyzing the obtained results. Such procedure is viable and relevant due to the following reasons:

target group is formed by expert auditors depending on the aims and criteria of an internal audit;

it releases the manager of a company unit, the object of an audit, from the viability to draw on the resources of a particular employee for the process control;

it provides an advance warning and informing of collaborators, members of the target group, when auditing the given object.

The target group consists of the head of the unit (the audit object), the deputy head (if present), the quality representative and engineering personnel.

When it is considered to carry out an internal audit, it is necessary to form an audit group taking into account expert skills essential for the audit goal achievement. It is important to provide a totally competent group by means of selecting the group members according to the required knowledge and skills.

\section{RESULT}

The next step is an electronic poll procedure. It is a process of getting and processing of information obtained from the members of a target group. It is conducted by means of a joint-stock company's local network in order to assess the results of functioning of a given audit object (the process of audit). The procedure of an electronic poll consists of the following:

to compile a list of questions and tests;

to carry out a target group poll;

to analyze data and figures.

Figure 2 shows a schematic representation of an electronic poll procedure in the form of a context diagram using the IDEF0 methodology of functional modeling. Integrated analysis and data processing consist of assessment of both the electronic polling data and audit findings on site.

This procedure is carried out by the group of expert auditors with the assistance of the technical engineer. When analyzing the information, the practice of brainstorming is used [6]. The basic principles of brainstorming are:

to state tasks, objectives and restrictions clearly (audit aims and criteria);

to make up a list of skillful participants in order to cover all the necessary fields and if needed to go outside the bounds (to provide the group competence and a detailed informative analysis).

During the procedure of an integrated data processing the group carries out the comparative analysis of polling information and the one received while auditing on site. When the group has to solve difficult problems the members of this group share their opinion and correct the mistakes of each other. Such mutual activity makes the work (including the audit process) more efficient.

This approach allows one to analyze the state and the results of an audit object (process) functioning in an integrated manner; to reveal problems and sticking points and to work out measures dealing not only with the given process of functioning improvement but with the process of an internal audit as well.

Management is responsible is responsible for building a sustainable system of an internal audit business process. It will contribute to the rise of the efficiency of company's activity and to the protection of shareholders' interests. But it is important to say that even if the system of an internal audit is professionally organized its efficiency needs to be assessed from the position of goals achievement and the economy.

The represented methodology describing how to carry out an internal audit of business processes will definitely simplify the process of a joint-stock company's internal audit. In addition to this the usage of the given methods should be accompanied by the working out of inner regulatory documents, the development and improvement of the inspection tools and procedures as well as the plan of relationships between the Internal Audit Service and other departments and units of the company.

When assessing an internal audit of business processes "from purchase to payment", first of all it is necessary to consider its capability to achieve the planned results. For practical implementation of the methodology of an internal audit of business processes "from purchase to payment" it is necessary to assess the results of work of the whole chain of business processes. The task is to determine how successful and efficient the process "Internal audit of business processes "from purchase to payment" is. Possible indicators, measurement methods and sources of information necessary for the analysis are shown in table 1. 


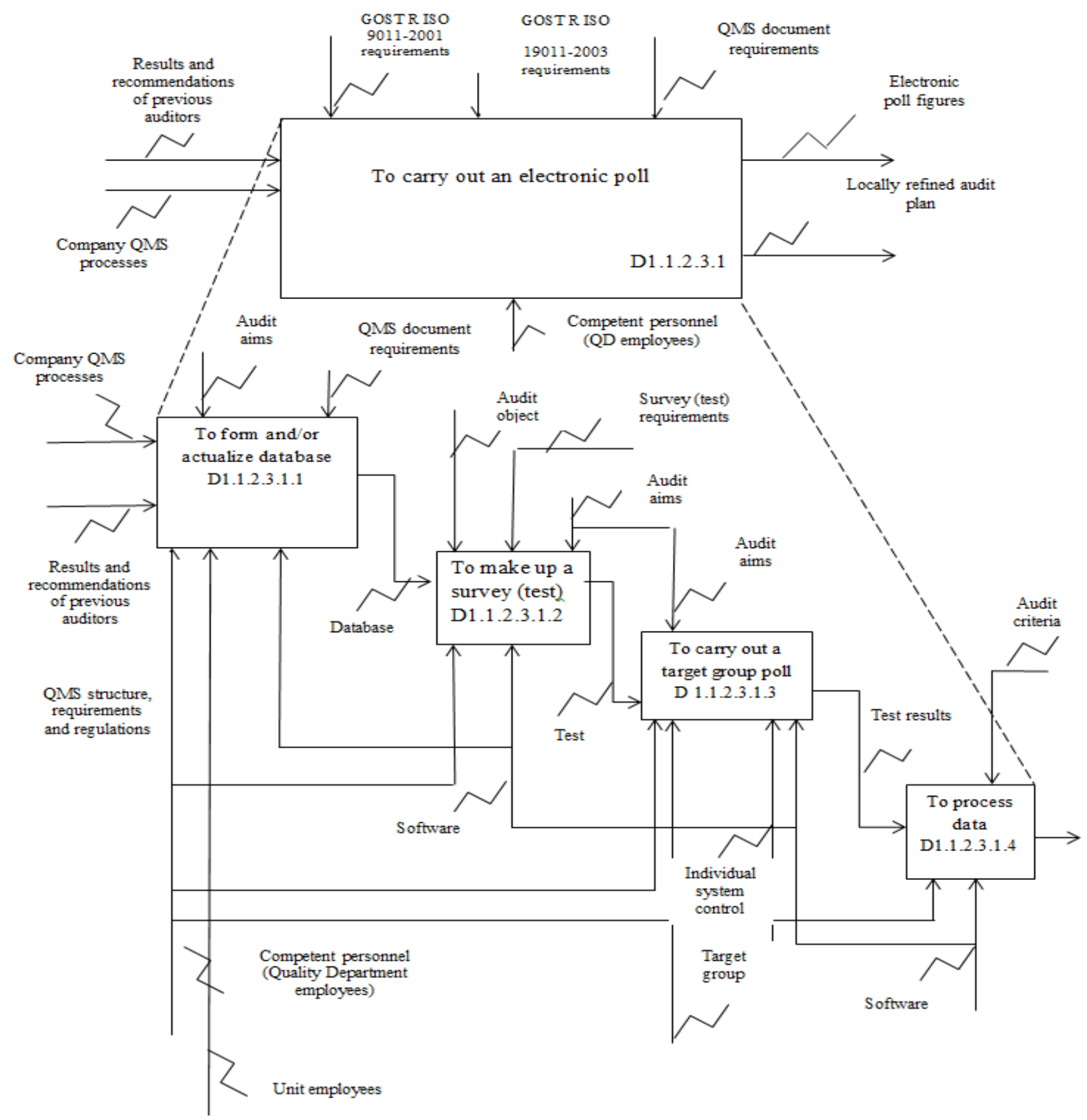

Fig. 2. Context diagram of an electronic poll procedure

TABLE I. EFFICIENCY INDICATORS OF THE PROCESS “INTERNAL AUDIT OF BUSINESS PROCESSES “FROM PURCHASE TO PAYMENT"

\begin{tabular}{|l|l|l|}
\hline \multicolumn{1}{|c|}{ Indicator } & \multicolumn{1}{|c|}{ Source of information } & \multicolumn{1}{c|}{ Measurement method } \\
\hline $\begin{array}{l}\text { The reduction in the number of repeated non- } \\
\text { compliances according to the audit results }\end{array}$ & Protocols and reports & The previous and reporting periods are compared \\
\hline $\begin{array}{l}\text { The absence of cases of untimely execution of } \\
\text { corrective actions }\end{array}$ & Protocols and reports & $\begin{array}{l}\text { The planned and actual dates of corrective actions are } \\
\text { compared }\end{array}$ \\
\hline $\begin{array}{l}\text { The efficiency of proposals for improving, made } \\
\text { by the auditors }\end{array}$ & Reports & $\begin{array}{l}\text { A survey of heads of departments (processes). Expert } \\
\text { assessment of the result achieved by means of } \\
\text { implementation of recommendations for improvement }\end{array}$ \\
\hline
\end{tabular}




\section{CONCLUSION}

For the process of "Internal audit of business processes "from purchase to payment", as well as for other process, the owner develops indicators for the assessment of efficiency. After that, numerical values are set for each indicator. The actual values of indicators are defined and registered. Determination of the effectiveness of the process "Internal audit of business processes "from purchase to payment" allows one to assess the functioning of the process, basing on the criteria approach and feedback.

\section{Reference}

[1] K. Namiri, N. Stojanovic, A semantic-based approach for compliance management of internal controls in business processes, CEUR Workshop Proceedings, 2007, no. 247, pp. 6164.

[2] J.L. Bierstaker, J.E. Hunton, J.C. Thibodeau, Do client-prepared internal control documentation and business process flowcharts help or hinder an auditor's ability to identify missing controls? 2009, Auditing, no. 28 (1), pp 79-94.

[3] M. Rosalyn, S.M. Uday, Consideration of risks and internal controls in business process modelling, Proceedings of the 15th European Conference on Information Systems, ECIS 2007, 2007, pp. 588-599.

[4] S.-M. Huang, D.C. Yen, Y.-C. Hung, Y.-J. Zhou, J.-S. Hua, A business process gap detecting mechanism between information system process flow and internal control flow, Decision Support Systems, 2009, no. 47 (4), pp. 436-454.

[5] R.P. Marques, C. Santos, Information systems with internal control on business processes: An approach based on an organizational engineering framework, Iberian Conference on Information Systems and Technologies, CISTI, 2016-July, 2016, art.no. 7521641

[6] I.I. Ismagilov, S.F. Khasanova, Algorithms of quasi evaluation of polynomial trend of the digital signals based on oblique discrete walsh transformations, 2016 2nd International Conference on Industrial Engineering, Applications and Manufacturing, ICIEAM $2016 \quad$ - Proceedings 2017. DOI: 10.1109/ICIEAM.2016.7911545/ 